\title{
Questions about dexamethasone use for the prevention of anti-SSA related congenital heart block
}

\author{
N Costedoat-Chalumeau, Z Amoura, D Le Thi Hong, B Wechsler, D Vauthier, \\ P Ghillani, T Papo, O Fain, L Musset, J-C Piette
}

Background: Mothers with anti-SSA/Ro antibodies who have had a previous fetus with congenital heart block (CHB) have a risk of recurrence estimated to be up to $16 \%$. Objective: To improve the management of these "high risk patients" by determining (a) whether or not prophylactic treatment is efficient; (b) whether or not fluorinated steroids (betametasone and dexamethasone) that do cross the placenta in an active form are safe for the fetus; and (c) which prophylactic treatment should be used.

Methods: Retrospective study performed on seven mothers sent to a university hospital owing to a past history of one (six mothers) or two children (one mother) with $\mathrm{CHB}$.

Results: 13 subsequent pregnancies occurred. No CHB was observed. All four pregnancies in women treated with $10 \mathrm{mg} /$ day prednisone were uneventful. Three pregnancies in women receiving no steroids resulted in two early spontaneous abortions and one live birth. The six pregnancies in women treated with dexamethasone (4-5 mg/day) ended in one early and one late spontaneous abortion, two stillbirths, and two live births with intrauterine growth restriction and mild adrenal insufficiency. A histological study of one stillbirth disclosed intrauterine growth restriction and marked adrenal hypoplasia.

Conclusion: Adverse obstetric outcomes were often seen here and major concerns have been raised by paediatricians about the safety of fluorinated steroids, owing to the results of animals studies, retrospective data, and randomised trials. Because fluorinated steroids have not been shown to improve prophylactic treatment of $\mathrm{CHB}$ in pregnant women at high risk, their use is questionable.

$\mathrm{P}$ regnant women with anti-SSA/Ro antibodies are at risk of delivering an infant with neonatal lupus syndrome. Neonatal lupus syndrome is characterised by transient lupus dermatitis, hepatic and haematological abnormalities, or isolated congenital heart block (CHB). ${ }^{1}$ The heart block is permanent, often requires a pacemaker, ${ }^{1}$ and may be complicated by late onset cardiomyopathy. If anti-SSA/Ro antibodies are present in the sera of pregnant women, the incidence of CHB in live births has been reported to be $2 \%$ in a recent prospective study. ${ }^{2}$ By contrast, the risk of recurrence of CHB in a subsequent child is estimated to be up to $16 \%$.

Attention has been focused on two different points: in utero treatment of established CHB and prophylactic treatment of mothers with anti-SSA/Ro antibodies to prevent the occurrence of CHB. Clearly, treatment is needed for the former because of the substantial morbidity and mortality of CHB. Increasing data indicate that treatment with fluorinated steroids (dexamethasone or betamethasone) that do cross the placenta in an active form is useful for fetuses with incomplete block or hydropic changes. ${ }^{3}$ It remains unclear whether treatment started immediately upon detection of a third-degree block is useful. Accordingly, Buyon et al have proposed guidelines for in utero treatment of established CHB. ${ }^{4}$

The problem of prophylactic treatment of CHB in pregnant patients with anti-SSA/Ro antibodies is less clear owing to the rarity of this complication. Shinohara et al have suggested that prenatal maintenance treatment with prednisolone or betamethasone given to the mother with anti-SSA/Ro antibodies and starting before 16 weeks' gestation might reduce the risk of developing CHB in the offspring. ${ }^{5}$ However, the retrospective nature of the study and potential referral bias preclude any firm conclusions. Additionally, the authors did not differentiate between prednisolone and betamethasone and considered that both treatments were efficient to prevent CHB. If equivalent to betamethasone, prednisone and prednisolone should be preferred, as they do not cross the placenta, and thus, would not affect the fetus. However, numerous case reports or series have described the occurrence of CHB despite prednisone or prednisolone treatment (unpublished data and the following references). ${ }^{367}$ Then, fluorinated steroids that do cross the placenta in an active form may be theoretically preferred. During the "Fourth international workshop on neonatal lupus syndromes and the Ro/SSA-La/SSB system" ${ }^{\prime 8}$ a protocol with randomisation of dexamethasone to anti-Ro positive mothers who had had no previous fetuses with CHB was proposed. This suggestion was controversial and stimulated considerable comment and debate among the rheumatologists attending the meeting. By contrast, dexamethasone or betamethasone prophylactic treatment of mothers who had had a previous fetus with CHB and were therefore at high risk of recurrence was proposed. ${ }^{8}$ However, little is known about the safety and effectiveness of this intervention.

We report our experience in prophylactic treatment used for pregnant women with anti-SSA/Ro antibodies who had had a previous fetus with $\mathrm{CHB}$ and we discuss the adverse effects of dexamethasone.

\section{PATIENTS AND METHODS \\ Patients}

This monocentric and retrospective study was performed in Pitié-Salpêtrière University hospital in France. Seven mothers were referred for a prior history of one (six mothers) or two children (one mother) affected by CHB (table 1). In all cases, CHB revealed the maternal anti-SSA/Ro antibodies status. Subsequently, these mothers were regularly monitored in our centre before becoming pregnant. During follow up, two patients met the American College of Rheumatology criteria for systemic lupus erythematosus (SLE), four met the European criteria for primary Sjögren's syndrome (SS), and one remains symptom free. Between January 1993 and January 2002, 13 subsequent pregnancies occurred spontaneously in these seven women. The mean age at pregnancy onset was 35 years (range 27-42). During pregnancy, patients were closely monitored by both an internist and a high risk pregnancy obstetric team, monthly until 32 weeks and then 
Table 1 Specific outcome of 13 pregnancies in seven women with anti-SSA/Ro antibodies who had previously had fetuses with $\mathrm{CHB}$

\begin{tabular}{|c|c|c|c|c|c|c|c|}
\hline $\begin{array}{l}\text { Patient } \\
\text { No }\end{array}$ & $\begin{array}{l}\text { Current maternal } \\
\text { diagnosis }\end{array}$ & Previous pregnancies with $\mathrm{CHB}$ & $\begin{array}{l}\text { Corticosteroid } \\
\text { treatment of following } \\
\text { pregnancies }\end{array}$ & $\begin{array}{l}\text { Outcome of following } \\
\text { pregnancies }\end{array}$ & Sex & $\begin{array}{l}\text { Gestational } \\
\text { age (WG) }\end{array}$ & $\begin{array}{l}\text { Birth } \\
\text { weight }(g)\end{array}$ \\
\hline \multirow[t]{2}{*}{1} & SLE & $1 \mathrm{CHB}$ (death at 2 days of life) & $\begin{array}{l}\text { Dexamethasone (4 } \\
\mathrm{mg} / \text { day) }\end{array}$ & Spontaneous abortion (15 WG) & - & - & - \\
\hline & & & $\begin{array}{l}\text { Prednisone (10 } \\
\mathrm{mg} / \text { day) }\end{array}$ & Live birth & $\mathrm{F}$ & 40 & 4130 \\
\hline \multirow[t]{3}{*}{2} & SLE & $1 \mathrm{CHB}$ (death at 6 months of life) & $\begin{array}{l}\text { Dexamethasone (4.5 } \\
\mathrm{mg} / \text { day) }\end{array}$ & Spontaneous abortion (18 WG) & - & - & - \\
\hline & & & $\begin{array}{l}\text { Dexamethasone (4.5 } \\
\mathrm{mg} / \text { day) }\end{array}$ & Stillbirth (24 WG) & - & - & - \\
\hline & & & $\begin{array}{l}\text { Prednisone (10 } \\
\mathrm{mg} / \text { day) }\end{array}$ & Live birth & $\mathrm{F}$ & 38 & 2680 \\
\hline \multirow[t]{2}{*}{3} & Primary SS & $\begin{array}{l}2 \mathrm{CHB} \text { (pacemaker in both } \\
\text { cases) }\end{array}$ & $\begin{array}{l}\text { Dexamethasone (4 } \\
\mathrm{mg} / \text { day) }\end{array}$ & Live birth (adrenal insufficiency) & M & 37 & $2140 *$ \\
\hline & & & $\begin{array}{l}\text { Dexamethasone (4 } \\
\mathrm{mg} / \text { day) }\end{array}$ & Live birth (adrenal insufficiency) & M & 37 & $1870 *$ \\
\hline \multirow[t]{2}{*}{4} & Symptom free & $1 \mathrm{CHB}$ (stillbirth at $30 \mathrm{WG}$ ) & None & Spontaneous abortion (11 WG) & - & - & - \\
\hline & & & None & Live birth & $\mathrm{F}$ & 40 & 4030 \\
\hline 5 & Primary SS & $\begin{array}{l}1 \mathrm{CHB} \text { (no need of pacemaker } \\
\text { at } 4 \text { years) }\end{array}$ & $\begin{array}{l}\text { Dexamethasone ( } 5 \\
\mathrm{mg} / \text { day) }\end{array}$ & $\begin{array}{l}\text { Stillbirth ( } 32 \text { WG) (adrenal } \\
\text { hypoplasia) }\end{array}$ & - & - & - \\
\hline 6 & Primary SS & $\begin{array}{l}1 \mathrm{CHB} \text { (no need of pacemaker } \\
\text { at } 10 \text { years) }\end{array}$ & $\begin{array}{l}\text { Prednisone (10 } \\
\text { mg/day) }\end{array}$ & Live birth & $\mathrm{F}$ & 39 & 2930 \\
\hline \multirow[t]{2}{*}{7} & $\begin{array}{l}\text { Primary SS + high } \\
\text { APL }\end{array}$ & $\begin{array}{l}1 \mathrm{CHB} \text { (pacemaker at } 18 \\
\text { months) }\end{array}$ & None & Spontaneous abortion (5 WG) & - & - & - \\
\hline & & & $\begin{array}{l}\text { Prednisone (10 } \\
\mathrm{mg} / \text { day) }\end{array}$ & Live birth & M & 39 & 3080 \\
\hline
\end{tabular}

*Intrauterine growth restriction (birth weight lower than the third centile for gestational age).

CHB, congenital heart block; WG, weeks' gestation; SLE, systemic lupus erythematosus; primary SS, primary Siögren's syndrome; APL, antiphospholipid antibodies.

every two weeks. Instrumental monitoring included repeated fetal echocardiography and Doppler velocimetry (every two weeks between 16 and 26 weeks' gestation).

\section{Autoantibody determination status}

Serum samples were tested using INNO-LIAT ANA Update (Innogenetics, provided by InGen, France), a semiquantitative line immunoassay for detection of antibodies against Ro 52 $\mathrm{kDa}$, Ro $60 \mathrm{kDa}$, and La. All patients were positive for anti-SSA/Ro $52 \mathrm{kDa}$ antibodies, six for anti-SSA/Ro $60 \mathrm{kDa}$ antibodies, and six for anti-SSB/La antibodies. Autoantibody status did not change during follow up.

\section{Treatments and follow up}

Treatment was not standardised. Upon the diagnosis of pregnancy, patients received either $10 \mathrm{mg} /$ day of prednisone (number of pregnancies 4), dexamethasone with a daily dose of $4 \mathrm{mg}(\mathrm{n}=3), 4.5 \mathrm{mg}(\mathrm{n}=2)$ or $5 \mathrm{mg}(\mathrm{n}=1)$, or no glucocorticoids $(n=3)$ (table 1$)$. Associated treatments were 100 $\mathrm{mg}$ /day aspirin $(\mathrm{n}=9)$ and hydroxychloroquine $(\mathrm{n}=7)$.

\section{RESULTS}

The outcome of the 13 pregnancies included four spontaneous abortions, two stillbirths, and seven live births (table 1). Repeated fetal echocardiography and Doppler velocimetry were performed in all cases and no CHB was seen. For the stillbirths, fetal echocardiography results were available within two weeks before birth and were normal. No other feature of neonatal lupus syndrome was noticed in the live births. All four pregnancies in women treated with prednisone were uneventful. The three pregnancies in women receiving no steroids resulted in two early spontaneous abortions and one live birth. The six pregnancies in women treated with dexamethasone ended in two spontaneous abortions, two stillbirths, and two live births with intrauterine growth restriction (birth weight lower than the third centile for gestational age) and mild adrenal insufficiency in both newborns. A histological study was performed on the product of one stillbirth (patient 5) and disclosed intrauterine growth restriction associated with marked adrenal hypoplasia.
Except for patient 7 with repeatedly high positive anticardiolipin antibodies, none of the other patients who underwent a miscarriage had significant antiphospholipid positivity.

Electrocardiograms were available for six children within the first week of life and the mean PR interval was $88 \mathrm{~ms}$ (range 80-100).

\section{DISCUSSION}

We did not observe any CHB in our series of pregnancy in women at high risk. However, the small number of women in each of the subgroups precludes any conclusions about the prophylactic role of steroids in CHB. The four pregnancies conducted under treatment with prednisone were uneventful. By contrast, we observed an unexpectedly high rate of adverse obstetric events in patients treated with dexamethasone, including spontaneous abortion, stillbirth, severe intrauterine growth restriction, and adrenal insufficiency/hypoplasia. Miscarriages and severe intrauterine growth restriction could not be explained by the association with an antiphospholipid syndrome as no patients receiving dexamethasone had significant antiphospholipid positivity. No other explanation (like viral infection) could be found, leading us to suspect a relationship with dexamethasone administration.

Accordingly, concerns have been raised about the safety of fluorinated steroids due to concordant animal studies, retrospective data, and randomised trials. Firstly, antenatal dexamethasone given to promote fetal maturation is associated with diminished birth weight. ${ }^{9}$ Secondly, brief prenatal exposure to dexamethasone has led to the development of hypertension, left ventricular hypertrophy, and reduced cardiac functional reserve in adult sheep. ${ }^{10}$ Clinically significant left ventricular myocardial hypertrophy has been recently reported in preterm humans neonates after an early short course of dexamethasone for neonatal chronic lung disease, ${ }^{11}$ and antenatal betamethasone treatment has been associated with higher systolic and diastolic blood pressures in adolescence. $^{12}$

However, the major concern is probably about the neurological effects of dexamethasone. Indeed, administration of 
dexamethasone in high doses to pregnant rhesus monkeys during the period corresponding to the early third trimester of human pregnancy induced degeneration and depletion of the hippocampal pyramidal and dentate granular neurones in the fetal brain. ${ }^{13}$ In humans, it has been suspected that fluorinated steroids used in utero to prevent virilisation of female fetuses affected by congenital adrenal hyperplasia induce adverse events, including severe growth retardation and delayed psychomotor development. ${ }^{14}{ }^{15}$ Additionally, markedly impaired growth of cerebral cortical gray matter has been recently reported in preterm neonates after an early short course of dexamethasone for neonatal chronic lung disease. ${ }^{16}$ In a meta-analysis, Barrington found that postnatal pharmacological steroid administration for prevention or treatment of bronchopulmonary dysplasia was associated with a dramatic increase in neuro-developmental impairment. ${ }^{17}$ The author proposed to abandon its use for this indication. ${ }^{17}$ Finally, Baud et al found that the adjusted odds ratio of cystic periventricular leucomalacia among very premature infants was 1.5 (95\% confidence interval 0.8 to 2.9) for the group of infants whose mothers had received dexamethasone as compared with the group of infants whose mothers had not received a glucocorticoid. ${ }^{18}$ By contrast, antenatal exposure to betamethasone was associated with a decreased risk of cystic periventricular leucomalacia. ${ }^{18}$ These results might be ascribed to the sulphites used as preservatives in dexamethasone, as emphasised by an in vitro experience on neuronal viability after exposure to steroids. ${ }^{19}$ In view of these results, the case of a former child (not included in this report) of patient 2, who was treated in utero with dexamethasone after discovery of CHB, is relevant. This child was admitted to hospital at 6 months of age for pulmonary infection. His condition rapidly deteriorated. Magnetic resonance imaging showed "unexpected" cerebral necrosis, and death occurred in the intensive care unit without clear explanation.

In conclusion, prophylactic regimens in pregnant women with anti-SSA/Ro antibodies should be closely evaluated. In the absence of a prior history of CHB, the risk of CHB is low as recently demonstrated. ${ }^{2}$ Depending on the mother's disease, abstention from, or a low dose of, prednisone seems to be the correct course if abnormal findings are not seen on close echocardiographic follow up; the latter should be performed between 16 and 24 weeks' gestation as emphasised by Buyon et al. ${ }^{1}$ Optimal management of women with a past history of $\mathrm{CHB}$ remains unclear as there is no convincing evidence for the use of steroids. A multicentre prospective study would be needed to answer this question. If steroids have to be used because of increasing concerns, prednisone is preferable and fluorinated steroids should be avoided. Finally, administration of fluorinated steroids in established $\mathrm{CHB}$ requires close evaluation of efficiency and fetal safety and, in accordance with the study by Baud et al, ${ }^{18}{ }^{19}$ betamethasone should probably be preferred to dexamethasone for this purpose.

\section{Authors' affiliations \\ N Costedoat-Chalumeau, Z Amoura, D Le Thi Hong, B Wechsler, \\ D Vauthier, P Ghillani, T Papo, O Fain, L Musset, J-C Piette, Centre Hospitalier, Universitaire Pitié-Salpêtrière, Paris, France}

Correspondence to: $\operatorname{Dr} N$ Costedoat-Chalumeau, 47-83 Bd de l'Hôpital, Centre Hospitalier, Universitaire Pitié-Salpêtrière, Paris 75013, France; nathalie.costedoat@psl.ap-hop-paris.fr

Accepted 22 January 2003

\section{REFERENCES}

1 Buyon JP, Hiebert R, Copel J, Craft J, Friedman D, Katholi M, et al. Autoimmune-associated congenital heart block: demographics, mortality, morbidity and recurrence rates obtained from a national neonatal lupus registry. J Am Coll Cardiol 1998;31:1658-66.

2 Brucato A, Frassi M, Franceschini F, Cimaz R, Faden D, Pisoni MP, et al. Risk of congenital complete heart block in newborns of mothers with anti-Ro/SSA antibodies detected by counterimmunoelectrophoresis: a prospective study of 100 women. Arthritis Rheum 2001;44:1832-5.

3 Saleeb S, Copel J, Friedman D, Buyon JP. Comparison of treatment with fluorinated glucocorticoids to the natural history of autoantibody-associated congenital heart block: retrospective review of the research registry for neonatal lupus. Arthritis Rheum 1999;42:2335-45.

4 Buyon JP, Copel JA, Friedman DM. Anti-SSA/Ro and -SSB/La antibodies. In: Miller $\mathrm{H}$, ed. Decision making in obstetrics. In press.

5 Shinohara K, Miyagawa S, Fujita T, Aono T, Kidoguchi K. Neonatal lupus erythematosus: results of maternal corticosteroid therapy. Obstet Gynecol 1999;93:952-7.

6 Waltuck J, Buyon JP. Autoantibody-associated congenital heart block: outcome in mothers and children. Ann Intern Med 1994;120:544-51.

7 Carreira PE, Gutierrez-Larraya F, Gomez-Reino JJ. Successful intrauterine therapy with dexamethasone for fetal myocarditis and heart block in a woman with systemic lupus erythematosus. J Rheumatol 1993;20: 1204-7

8 Brucato A, Buyon JP, Horsfall AC, Lee LA, Reichlin M. Fourth international workshop on neonatal lupus syndromes and the Ro/SSA-La/SSB System. Clin Exp Rheumatol 1999;17:130-6.

9 Bloom SL, Sheffield JS, McIntire DD, Leveno KJ. Antenatal dexamethasone and decreased birth weight. Obstet Gynecol 2001;97:485-90.

10 Dodic M, Samuel C, Moritz K, Wintour EM, Morgan J, Grigg L, et al. Impaired cardiac functional reserve and left ventricular hypertrophy in adult sheep after prenatal dexamethasone exposure. Circ Res 2001;89:623-9.

11 Zecca E, Papacci P, Maggio L, Gallini F, Elia S, De Rosa G, et al. Cardiac adverse effects of early dexamethasone treatment in preterm infants: a randomized clinical trial. J Clin Pharmacol 2001;41:1075-81.

12 Doyle LW, Ford GW, Davis NM, Callanan C. Antenatal corticosteroid therapy and blood pressure at 14 years of age in preterm children. Clin Sci (Colch) 2000;98:137-42.

13 Uno H, Lohmiller L, Thieme C, Kemnitz JW, Engle M, Roecker EB, et al. Brain damage induced by prenatal exposure to dexamethasone in fetal rhesus macaques. I. Hippocampus. Brain Res Dev Brain Res 1990;53:157-67.

14 Miller WL. Dexamethasone treatment of congenital adrenal hyperplasia in utero: an experimental therapy of unproven safety. J Urol $1999 ; 162: 537-40$

15 Lajic S, Wedell A, Bui TH, Ritzen EM, Holst M. Long-term somatic follow-up of prenatally treated children with congenital adrenal hyperplasia. J Clin Endocrinol Metab 1998;83:3872-80.

16 Murphy BP, Inder TE, Huppi PS, Warfield S, Zientara GP, Kikinis R, et al. Impaired cerebral cortical gray matter growth after treatment with dexamethasone for neonatal chronic lung disease. Pediatrics 2001;107:217-21.

17 Barrington KJ. The adverse neuro-developmental effects of postnatal steroids in the preterm infant: a systematic review of RCTs. BMC Pediatr $2001 ; 1: 1$.

18 Baud O, Foix-L'Helias L, Kaminski M, Audibert F, Jarreau PH, Papiernik $\mathrm{E}$, et al. Antenatal glucocorticoid treatment and cystic periventricular leukomalacia in very premature infants. $N$ Engl J Med 1999;341:1190-6.

19 Baud O, Laudenbach V, Evrard P, Gressens P. Neurotoxic effects of fluorinated glucocorticoid preparations on the developing mouse brain: role of preservatives. Pediatr Res 2001;50:706-11. 